
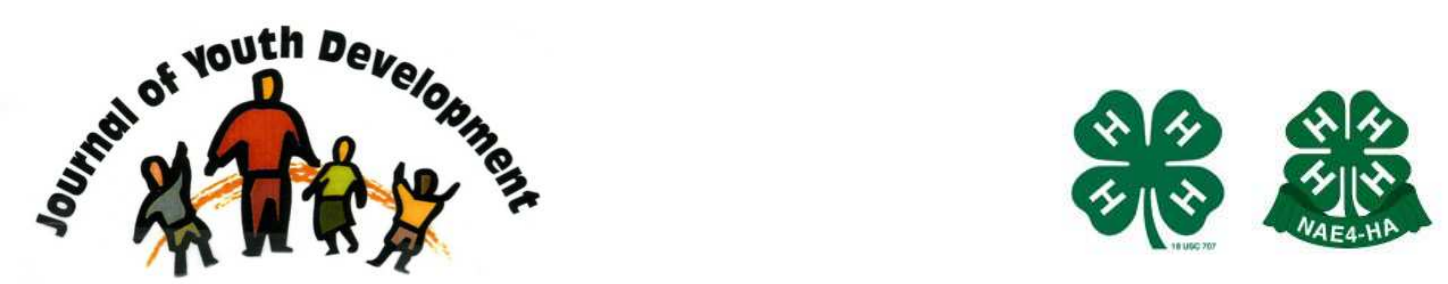

\title{
Out-of-School Time Activity Participation, School Engagement and Positive Youth Development: Findings from the 4-H Study of Positive Youth Development
}

\author{
Yibing Li \\ Tufts University \\ Medford, MA \\ Yibing.Li@Tufts.edu \\ Neda Bebiroglu \\ Tufts University \\ Medford, MA \\ Erin Phelps \\ Tufts University \\ Medford, MA \\ Richard M. Lerner \\ Tufts University \\ Medford, MA \\ richard.lerner@tufts.edu
}

Jacqueline V. Lerner

Boston College School of Education

Chesthill, MA

lernerj@bc.edu 


\title{
JOURNAL OF YOUTH DEVELOPMENT \\ bridging research and practice

\section{Out-of-School Time Activity Participation, School Engagement and Positive Youth Development: Findings from the 4-H Study of Positive Youth Development}

Yibing Li, Neda Bebiroglu, Erin Phelps and Richard M. Lerner Tufts University

Jacqueline V. Lerner

Boston College Lynch School of Education

\begin{abstract}
The relations in early adolescence among out-of-school-time activities and indicators of youth development were assessed through the use of 8th grade data from the longitudinal, 4-H Study of Positive Youth Development. Hierarchical multiple linear regressions indicated that "hanging out" with friends without set plans and excessive media use were associated with lower behavioral engagement with school, lower academic achievement, and higher rates of risk behaviors. Youth who ate dinner with their family reported higher levels of emotional engagement, lower depression and risk behaviors, and better grades. Engagement in civic activities was associated with higher levels of emotional engagement. Behavioral and emotional engagement were both associated with better grades and lower depression. Emotional school engagement was also associated with lower rates of risk behaviors. Implications of the findings for evaluating the role of out-ofschool-time activities and behavioral and/or emotional school engagement in academic achievement and youth development are discussed.
\end{abstract}




\section{Introduction}

The old adage, "Idle hands are the devil's tools" reads, on the other side of the provincial coin, "Angels hover about the busy." Similarly, people believe that adolescents are more likely to get involved in risky activities when they are bored and have nothing to do (Eccles, \& Barber, 1999). This folk wisdom has been supported by studies of the connections between adolescents' out-of-school time (OST) activities and individual and social adjustment (e.g., Eccles, 2005; Mahoney, Harris, \& Eccles, 2006).

Most of the studies on OST have focused on the impacts of structured activities, varying from sports and clubs, to youth development (YD) programs on adolescents' adjustment (Lerner, 2004, 2007). Findings demonstrate that participation in structured OST activities has positive consequences for youth development (e.g., Mahoney, et al., 2006). For example, many adolescents participate in civic activities, such as volunteering and peer mentoring. These activities not only teach youth basic skills needed for later development, but they also give them opportunities to connect to their community and to practice democracy through collective work (Flanagan \& Faison, 2001; Verba, Schlozman, \& Brady, 1995). Youth participation in these activities is linked to their later political participation and is considered to be an indicative of their potential contributions to society (Lerner, 2004).

Structured OST activities may be particularly important for success in the school context. The key argument is that structured OST activities provide youth a safe environment, adult supervision, supportive peer relationships, and a variety of training opportunities (Larson, Hansen, \& Moneta, 2006; Sherrod, 2007), which are all essential elements for school. Meaningful involvement in such OST activities presents informal "developmental contexts" for youth to learn and grow, and may serve to support school involvement and enhance the impact of school on positive development.

Given the potential importance of structured OST activities for school, one may propose that structured OST activities have the potential to foster school engagement. School engagement manifests itself in youth's behavioral involvement and emotional identification with school (Finn \& Rock, 1997). Youth who are behaviorally engaged with school tend to have higher academic performance, display fewer discipline problems, and are more likely to complete high school (Fredricks, Blumenfeld, \& Paris, 2004). Lack of emotional engagement with school, on the other hand, is one of the most important reasons for youth to drop out (Finn, 1991). Therefore, both behavioral and emotional school engagement are believed to be antidotes to underachievement, student boredom, and dropout (Fredricks, Blumenfeld, \& Paris, 2004).

Recent research indicates that participation in structured OST activities predicts school engagement and other indicators of positive youth development (PYD), such as self esteem and high educational aspiration (Eccles, \& Barber, 1999). In particular, youth development (YD) programs, an instance of structured OST activities that emphasizes sustained, positive adultyouth relations, life skill-building activities, and youth participation in and leadership of various community activities, are particularly related to instances of PYD, or one or more of the "Five Cs" of this development, i.e., Competence, Confidence, Character, Character, and Caring (e.g., Roth, \& Brooks-Gunn, 2003; Zarett, et al., in press). 
Given all the possible positive effects of structured OST activities, and more specifically, of YD programs (Mahoney, Parente, \& Zigler, in press), educators, practitioners, and developmental scientists have been looking beyond the typical school day to create structured opportunities for fostering skill learning and positive youth development (Jordan, \& Nettles, 2000). However, the reality is that structured OST activities are not the only component of the OST experiences of American youth. Adolescents are involved in many unstructured activities, in and out of school, with others and alone. These alternative activities may consume at least as much time (Mahoney et al., 2006). For instance, youth may spend at least one-third of their daily time sleeping, some time participating in structured out-of-school time activities, about a quarter of time being in school (not counting travel time to and from school), and the rest of their time (less than 10 hours a day) devoted to a set of activities that include eating meals, doing homework, watching television, or hanging out with friends.

All of these latter unstructured activities may have developmental consequences. These consequences can sometimes be positive. For instance, family meals may provide opportunities for parents to model, coach, and monitor their youth and, as well, may offer opportunities for youngsters to review and reinforce their out-of-home experiences, and provide opportunities for child development and socialization (Larson, Branscomb, \& Wiley, 2006). Youth who regularly eat dinners with their families are less likely to engage in risk behaviors, have low self esteem, manifest lower depression (Compan, Moreno, Ruiz, \& Pascual, 2002; Eisenberg, Olson, Neumark-Sztainer, Story, \& Bearinger, 2004; Theokes, \& Lerner, 2006). On the other hand, unstructured activities can have negative developmental consequences. For instance, watching television has been found to be negatively linked to school engagement: Youth who spend less time watching television are less likely to feel bored by, and more likely to be engaged with, school (Dotterer, McHale, \& Crouter, 2007).

Thus, we need to assess the impact of youth OST activities beyond those linked to structured programs such as sports, clubs, or YD programs (Zarrett, \& Eccles, 2006). This broadened approach to understanding the impact of youth participation in structured and unstructured OST activities is important because young people do not grow up in programs but in families, schools, and neighborhoods, where they are involved in various unstructured activities. These various unstructured activities in which adolescents participate may influence the intensity and quality of their engagement in school. As such, researchers and practitioners need to put youth back into their family, school, and neighborhood, and understand the impact of how they make use of all of their time.

Accordingly, in the current study, we expanded the spectrum of youth OST activities by studying various activities such as television watching, surfing online, hanging out with friends, eating dinner with family, and volunteering. In addition, studies on school engagement have most often focused on its connections to academic outcomes, such as grades and test scores, which reflect a narrow view of youth educational experience (Wong, \& Rowley, 2001). Thus, in the present study, we investigated the effects of school engagement beyond academic outcomes by including indexes of depression and risk behavior. Finally, in order to examine the effects of structured and unstructured OST activities on multiple indicators of youth development, we included measures of academic achievement, depression, and risk behaviors.

The present study examined how youth engagement in structured and unstructured out-ofschool-time activities, and particularly civic activities, was associated with increased academic 
achievement and emotional and behavioral development, and assessed the roles of behavioral and emotional school engagement in affecting the relations between activity participation, academic performance, and emotional and behavioral indicators of youth development.

We expected that:

(1) Being engaged with structured and unstructured activities such as family meals, exercising, and civic activities would be positively associated with favorable youth development, whereas participation in unstructured entertainment activities such as hanging out with friends and media use (TV watching, playing video games) would be negatively associated with positive indicators of youth development; that

(2) youth, through participating in civic activities (i.e., helping, volunteering, and tutoring), would benefit themselves in terms of academic achievement and other indicators of development; and that

(3) school engagement could be promoted through out-of-school time activities and would be predictive of academic achievement and other aspects of positive youth development.

\section{Method}

The present study was conducted as a part of the 4-H Study of Positive Youth Development (PYD), which is a multi-wave longitudinal investigation in the United States that started in 2002 by assessing 5th grade youth and their parents. This report presents data derived from a Student Questionnaire (SQ) administrated during the fourth wave of the 4-H Study, i.e., during eighth grade. Full details of the methodology of the 4-H study have been presented in prior reports (Jelicic, Bobek, Phelps, Lerner, \& Lerner, 2007; Lerner, et al., 2005). Accordingly, we present here those features of methodology pertinent to the focus of this investigation.

\section{Participants}

The present paper is based on Grade 8 participants in the 4-H study who were sampled from 24 states across the nation. This sample is comprised of a cross-sectional group of 1,567 adolescents (62.0\% female). The mean age of youth in this sample was 14.21 years (SD $=0.76$ Years). Socioeconomic status (SES) is indexed as family income ( $M=\$ 63,683, \mathrm{SD}=\$ 36,092)$ and mother's education ( $M=14.21$ years, $S D=0.76$ years). In the current study we controlled for sex and mother's education in all analyses reported. The sample was largely European American (71.0\%), but included 8.8\% Latino/a American, 8.4\% African American, 3.0\% Asian American, $2.0 \%$ Native American, and 3.6\% multi-ethnic/racial American youth.

\section{Measures}

There were many standard demographic questions about youth and their families (date of birth, sex, race/ethnicity, and so forth). In addition to the demographic measures, the present study used measures of the assessment of the behavioral and emotional school engagement, youth's participation in out-of-school time activities, grades, depression, and risk behaviors. All of the non-demographic measures employed in this paper come from the Student Questionnaire (SQ).

Participation in Out-of-School Time Activities. Youth participation in out-of-school time activities was assessed by questions pertaining to 19 activities (see Table 1). We categorized these out-of-school time activities into six types for the analyses: Youth Development (YD) 
programs, civic activities, exercise, hanging out with friends, family dinner, and passive media use (see Table 1). Items indicate whether the student participates in specific activities (e.g., watching television or volunteering) or programs offered by youth development organizations in the current year and whether he or she was involved in these activities or programs in the past. Frequency of participation in these activities is also measured ( $0=$ never to $5=$ every day).

Table 1

Participation in out-of-school time activities in Grade 8

\begin{tabular}{|l|l|}
\hline Type of Activity & Individual Activities \\
\hline YD Programs & $\begin{array}{l}\text { 4-H Club and 4-H Afterschool Programs } \\
\text { Boys Scouts and Girl Scouts } \\
\text { YMCA and YWCA } \\
\text { Big Brothers and Big Sisters } \\
\text { Boys and Girls Club } \\
\text { Local Youth Center }\end{array}$ \\
\hline Civic Activity & $\begin{array}{l}\text { Volunteering Your Time } \\
\text { Mentoring/Peer/Advising } \\
\text { Tutoring } \\
\text { Helping at church } \\
\text { Helping at school } \\
\text { Helping a neighbor } \\
\text { Being a leader in a group or organization }\end{array}$ \\
\hline Exercise & $\begin{array}{l}\text { Exercising or being physically active } \\
\text { Passive media use }\end{array}$ \\
\hline Family Dinners & $\begin{array}{l}\text { Watching TV } \\
\text { Playing video games } \\
\text { On the internet }\end{array}$ \\
\hline Hang out & Having dinner with the whole family \\
\hline & Hang out with friends with no set plan \\
\hline
\end{tabular}

Youth Development (YD) programs included several programs such as 4-H club and afterschool programs, Boys \& Girls Club, Big Brothers/Big Sisters, and local youth center activities. For the purpose of our analysis, if youth responded yes to any of these items, they were considered a YD program participant.

Civic engagement was measured by eight items using questions adapted from the Profiles of Student Life: Attitudes and Behaviors (PSL-AB), created by the Search Institute (Leffert, et al., 1998). Four items assessed how often youth helped a neighbor, at school and church; three items assessed the frequency of their service activity participation (e.g., "how often do you do mentoring/peer advising?") and one item assessed how often the youth had been a leader in the last year. Items were weighted equally and were summed up, with higher scores indicating higher levels of engagement. 
Passive media use was measured by three items that asked how often a youth watched TV, played video games and was on the internet per week. Items were weighted equally and were summed up into a composite for passive media use.

Family dinner, "hanging out" with friends, and exercise were all measured by single items that asked the number of times a youth had dinner with his or her family, and the amount of time they spent hanging out with his or her friends without a set plan and doing exercise.

School Engagement: Behavioral and Emotional. Six school engagement items were included in the analysis. All items were from the PSL-AB, created by the Search Institute (Leffert, et al., 1998). The items asked youth about behaviors that pertained to academic functioning and to their emotions about school. For example, youth were asked whether they attended school regularly, whether they went to school without homework completed, and whether they thought their teachers and schoolmates cared about them. The response formats of three items were from $1=$ strongly disagree to $5=$ strongly agree. The other three items were with 1 = usually to $3=$ seldom. In order to create consistency in item scoring, the three items with 1 to 3 response format were recoded as 1 to 5 . In addition, the item "I do not care about school" was reverse-coded; thus, higher scores indicated higher engagement levels for all items.

Academic Achievement. Academic achievement was indexed by a single item that questioned "What grades do you earn in school?" which had a forced choice response format that ranged from $1=$ Mostly As to $8=$ Mostly below Ds.

Risk Behavior. Risk behaviors that are pertinent to substance use and delinquency were assessed using questions adapted from the PSL-AB and from the Monitoring the Future questionnaire (Bachman, Johnson, \& O'Malley, 2000). Five items assessed the frequency of substance use (e.g., alcohol) in the last year $(a=0.86)$. Four items assessed the frequency of delinquent behaviors (e.g., "how many times have you hit or beat up someone?") during the last year $(a=0.73)$. Items from these two scales were weighted equally and combined into a composite for risk behaviors.

Depression. Depression was measured by the 20-item Center for Epidemiological Studies Depression Scale (CES-D; Radloff, 1977). Youth reported how often they felt a particular way during the past week. An example of questions is: "I was bothered by things that usually don't bother me." The forced choice response format ranges from $1=$ rarely or none of the time to $4=$ most or all of the time. Participants reported how often they felt a particular way during the past week. Items were recoded to range from 0 to 3 and summed for a total score, with higher scores indicating higher levels of depression. Potential scores range from 0 to 60.

\section{Procedure}

Youth were tested in groups within their schools (in about $80 \%$ of the cases) or after-school programs. Trained study staff or assistants, who began all testing sessions by reading the instructions to the participants, conducted data collection. Parent data were collected through teachers or program staff giving youth an envelope to take home to their parents/guardians. The envelope contained a letter that introduces the study, consent forms for the child and 
his/her parent, a parent questionnaire, and a stamped self-addressed envelope for returning the completed forms and parent questionnaire.

\section{Results}

Our analyses were conducted to advance understanding of the association between activity participation, behavioral and emotional school engagement, and indicators of youth development. These indicators are indexed by grades, depression, and risk behaviors. The second goal was to examine the role of school engagement in the relations between activity involvement and youth development. Listwise deletion of cases was used to account for missing data in the following analyses. Table 2 shows means and standard deviations for participation in out-of-school time activities, behavioral and emotional school engagement, and indicators of youth development at eighth grade.

Table 2

Means and standard deviations for activity participation, school engagement, and indicators of youth development in Grade 8

\begin{tabular}{|l|r|r|r|r|r|}
\hline & \multicolumn{1}{|c|}{$\mathrm{N}$} & Minimum & \multicolumn{1}{|c|}{ Maximum } & \multicolumn{1}{l|}{ M } & \multicolumn{1}{c|}{ SD } \\
\hline Risk Behaviors (range 0-30) & \multicolumn{1}{|c|}{1494} & .00 & 30.00 & 1.99 & 3.60 \\
\hline Depression (range 0-60) & \multicolumn{1}{|c|}{1497} & .00 & 51.00 & 13.87 & 9.65 \\
\hline Grades & \multicolumn{1}{|c|}{1482} & .5 & 4.0 & 3.32 & .76 \\
\hline Behavioral engagement & \multicolumn{1}{|c|}{1504} & 1.00 & 5.00 & 3.18 & .77 \\
\hline Emotional engagement & 1563 & 1.00 & 5.00 & 3.64 & .83 \\
\hline Youth Development program & 1518 & .00 & 1.00 & 0.60 & 0.49 \\
\hline Exercising & 1525 & 0 & 5 & 1.91 & 1.09 \\
\hline Family Dinners & 1503 & 1.00 & 7.00 & 5.20 & 1.66 \\
\hline Passive media use & 1540 & .00 & 15.00 & 4.49 & 2.51 \\
\hline Civic Activity & 1559 & .00 & 34.00 & 10.31 & 5.82 \\
\hline Hang out with friends & 1480 & 0 & 5 & 2.44 & 1.60 \\
\hline
\end{tabular}




\section{Bivariate correlations between activity participation, school engagement and indicators of youth development}

As shown in Table 3, participation in Youth Development (YD) program was not only significantly correlated with more time spent on exercising, and less time on passive media use, but was also correlated with higher levels of youth civic engagement and higher levels of behavioral and emotional engagement with school. In addition, YD program participation was also associated with better grades and fewer risk behaviors. On the other hand, passive media use was negatively correlated with every indictor of positive development and was positively correlated with higher levels of depression and risk behaviors.

\section{Table 3}

Correlations among activity participation, school engagement, grades, depression, and risk behaviors for Grade 8

\begin{tabular}{|c|c|c|c|c|c|c|c|c|c|c|}
\hline & YD & Exercising & \begin{tabular}{|l|} 
Family \\
Dinners
\end{tabular} & $\begin{array}{c}\text { Media } \\
\text { use }\end{array}$ & $\begin{array}{c}\text { Civic } \\
\text { activity }\end{array}$ & Hangout & \begin{tabular}{|c|} 
Behavioral \\
engagement
\end{tabular} & $\begin{array}{c}\text { Emotional } \\
\text { engagement }\end{array}$ & Grades & $\begin{array}{c}\text { Risk } \\
\text { Behaviors }\end{array}$ \\
\hline Exercising & $.082^{*}$ & & & & & & & & & \\
\hline Family Dinner & .015 & .027 & & & & & & & & \\
\hline Passive media use & $-.112^{*}$ & .040 & $-.127^{*}$ & & & & & & & \\
\hline Civic engagement & $.302^{*}$ & $.230^{*}$ & $.059^{*}$ & $\begin{array}{c}- \\
.162^{*}\end{array}$ & & & & & & \\
\hline $\begin{array}{l}\text { Hang out with } \\
\text { friends }\end{array}$ & -.048 & $.135^{*}$ & $-.108^{*}$ & $.117^{*}$ & .027 & & & & & \\
\hline $\begin{array}{l}\text { Behavioral } \\
\text { engagement }\end{array}$ & -.012 & -.002 & $.131^{*}$ & $\begin{array}{c}- \\
.160^{*}\end{array}$ & $.079^{*}$ & $-.174^{*}$ & & & & \\
\hline \begin{tabular}{|l} 
Emotional \\
engagement
\end{tabular} & $.120^{*}$ & .018 & $.183^{*}$ &.$-221^{*}$ & $.349^{*}$ & -.065 & $.189^{*}$ & & & \\
\hline Grades & $.115^{*}$ & .031 & $.210^{*}$ & 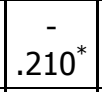 & $.288^{*}$ & $-.120^{*}$ & $.262^{*}$ & $.378^{*}$ & & \\
\hline Risk behavior & -.061 & .047 & $-.179^{*}$ & $.153^{*}$ & $-.135^{*}$ & $.214^{*}$ & $-.151^{*}$ & $-.356^{*}$ & $-.355^{*}$ & \\
\hline Depression & -.026 & $-.097^{*}$ & $-.176^{*}$ & $.152^{*}$ & -.063 & .033 & $-.209^{*}$ & $-.256^{*}$ & $-.257^{*}$ & $.204^{*}$ \\
\hline
\end{tabular}

The Effects of Activity Participation on Behavioral and Emotional School Engagement

Ordinary least squares regressions were computed, with behavioral and emotional school engagement as the outcome variables. The models included demographic variables: sex and mother's education, and activity participation variables: YD program participation, exercising, family dinners, media use, hangout, and civic activity.

As shown in Table 4, for behavioral school engagement, mother's education emerged as statistically significant. Youth whose mother had received more years of education were more likely than youth whose mother with lower education to be behaviorally engaged with school. Youth who went out with friends with no set plans and who reported more frequent use of media had significantly lower levels of behavioral engagement with school, above and beyond 
the effects of demographic variables. YD program participation, civic activity, and having dinner with family were not significantly associated with one's level of behavioral engagement.

For emotional school engagement, mother's education also turned out to be significant predictors of emotional engagement. Youth whose mother had received more education were significantly more emotionally engaged with school. The results indicated that youth who ate dinner with their families and youth who were more civically engaged were more likely to be emotionally engaged with their school than youth who had dinners with families less frequently and youth who were less involved in civic activities. In addition, youth who spent more time watching TV, playing video games or surfing online were significantly less emotionally engaged with school than their less frequent media usage peers (see Table 4).

\section{Table 4}

Parameter estimates, approximate $p$ values and goodness-of-fit tests for regression models of the relations between activity participation and school engagement, controlling for the effects of sex and mother's education

\begin{tabular}{|c|c|c|}
\hline Variable Names & Behavioral Engagement & Emotional Engagement \\
\hline & B & B \\
\hline Constant & $2.71^{*}$ & $2.71^{*}$ \\
\hline \multicolumn{3}{|l|}{ Demographics } \\
\hline Sex (1=female) & .09 & .13 \\
\hline Mother Education & $.04 *$ & $.03 *$ \\
\hline \multicolumn{3}{|l|}{ Activity Participation } \\
\hline YD participation & -.07 & -.06 \\
\hline Exercise & -.02 & -.04 \\
\hline Family dinner & .03 & $.07 *$ \\
\hline Passive media use & -.03 & $-.04 *$ \\
\hline Hang out & $-.06 *$ & $-.04 *$ \\
\hline Civic activity & .01 & $.04 *$ \\
\hline Model $\mathrm{R}^{2}$ & $.06 *$ & $.17^{*}$ \\
\hline Df (Residual) & 855 & 879 \\
\hline
\end{tabular}

Note. ${ }^{*}$ p.01 or less

The Effects of Activity Participation on Academic Achievement, Depression, and Risk Behaviors

The associations between activity participation and indicators of youth development were assessed by three ordinary least squares regression models, with grades, depression, and risk behavior as the respective outcome variables. Mother's education turned out to be a significant predictor of youth academic achievement (indexed by self-report grades) and depression, in a way that youth reported better grades and higher levels of depression when their mother received more years of education. Girls reported higher levels of depression and lower rates of risk behavior than boys. 
Regression results are summarized in Table 5 . Having dinner with family was a positive predictor of youth academic achievement, indicating that once demographic variables were accounted for, youth who ate dinner with family members more frequently reported better grades in school. They were also less depressed and were less likely to engage in risk behaviors than those who had family dinner less frequently. In addition, youth who spent more time using media or hanging out with friends with no set plans had lower levels of academic achievement and were more likely to manifest risk behaviors than those who reported less media use or spent less time with friends. Youth who were actively engaged in civic activities reported better grades at school.

\section{Table 5}

Parameter estimates, approximate $p$ values and good-of-fit tests for regression models of the relations between activity participation, school engagement and academic achievement, depression, and risk behaviors, controlling for the effects of sex and mother's education

\begin{tabular}{|l|c|c|c|}
\hline Variables & Risk behavior & Depression & Grades \\
& & & \\
& & $\mathrm{B} * *$ & $\mathrm{~B}$ \\
\hline Constant & $7.85^{*}$ & $34.72^{*}$ & $.77^{*}$ \\
\hline Demographics & & & \\
Sex (1=female) & -0.55 & $4.30^{*}$ & 0.00 \\
Mother's Education & -0.09 & $-0.37^{*}$ & $.06^{*}$ \\
\hline Activity Participation & & & \\
YD & .04 & -.54 & .01 \\
Exercise & .19 & $-0.92^{*}$ & .00 \\
Family dinner & $-0.29^{*}$ & $-0.93^{*}$ & $.06^{*}$ \\
Media use & $.14^{*}$ & $0.62^{*}$ & -.02 \\
Hang out & $0.34^{*}$ & 0.02 & -0.02 \\
Civic Activity & 0.00 & 0.13 & $0.02^{*}$ \\
\hline School Engagement & & & $.20^{*}$ \\
Behavioral Engagement & -0.11 & $-1.56^{*}$ & $.22^{*}$ \\
Emotional Engagement & $-1.16^{*}$ & $-2.99^{*}$ & $.27^{*}$ \\
Model R & $0.19^{2}$ & $0.23^{*}$ & 829 \\
df (Residual) & 836 & 832 & \\
\hline
\end{tabular}

Note: ${ }^{*} p<.01$ or less; ${ }^{* *} B=$ unstandardized beta coefficient

\section{The Association between School Engagement, Grades, Risk Behaviors, and Depression}

As can be see in Table 5, the results indicate that youth who were behaviorally engaged with school tended to have better grades at school and reported lower levels of depression, when the effects of demographics were taken into account, above and beyond the effects of all outof-school time activities. Youth who were emotionally engaged with school reported better grades, lower levels of depression and were less likely to be involved in risk behaviors than those who were emotionally disengaged from school activities. 


\section{Summary of the Findings}

In sum, the present findings indicated that participation in constructive activities such as YD programs, civic activities, and having dinner with the family was positively associated with youth school engagement and grades. Frequent media use and "hanging out" with friends were associated with lower behavioral and emotional school engagement, higher risk behavior and depression, and lower grades. Moreover, youth who were more behaviorally and emotionally engaged in school reported significantly better grades and lower levels of depression. Emotional school engagement was also associated with lower rates of risk behavior.

\section{Discussion}

The primary aim of the present report was to examine if the choices youth make regarding their participation in structured and unstructured activities are connected in meaningful ways to their school engagement, academic achievement, and broader indicators of youth development. Accordingly, this research augments the out-of-school time activity literature by expanding understanding of the potential impact of out-of-school activities (structured and unstructured) and school engagement in the promotion of healthy and positive youth development. These issues were considered using hierarchical regression models. The major findings and implications are reviewed below.

In general, the results indicated that participation in constructive activities, such as YD programs, civic activities, and having dinner with the family was negatively associated with youth participation in more "passive" activities, such as "hanging out" with friends and media use. For example, youth who participated in YD programs were more likely to exercise and to be engaged in civic activities, and less likely to spend time watching TV, playing video games, or using the internet. This negative linear relation between participations in constructive activities and "passive" unstructured activities implies that the more adolescents are provided meaningful activities and positive adult supervision when they are not in school, the less likely they are to be idle or to be involved in activities that distract them from opportunities for positive development.

Despite the recent surge of public and research interest in the effects of out-of-school activity participation on youth development, the question of how participation impacts school engagement has been overlooked, or assumed without testing. The present study is one of the first to bridge the out-of-school and the within-school worlds. The findings provide evidence that youth who involve themselves in positive, constructive activities (e.g., family dinner and civic activities) are more likely to be emotionally engaged with school than those who are less involved in these activities. In other words, this study suggests that how youth spend time outof-school has an impact on how they spend time in school, which in turn might lead to different academic and psychological outcomes. Accordingly, the importance of family, community, and program efforts in creating positive experiences for youth beyond the regular school time needs to be highlighted. Creating an effective partnership between in- and out-of-school educators may enhance meaningful involvement and effortful investment in school (Lerner, 2007).

The hypothesis that youth participation in structured and unstructured out-of-school time activities is predictive of a variety of indicators of youth development was corroborated by findings that consistently suggested positive effects of having dinner with the family on academic achievement and on lower rates of depression and risk behaviors. Conversely, there 
were significant negative effects associated with time spent watching TV, playing games, surfing online, and hanging out with friends. The results also highlight the advantages of participation in civic activities for improving academic achievement and the effects of exercising for lowering the levels of depression among youth. In light of these results, it is important to note that structured activities such as after-school programs are embedded in social and familial ecologies for youth (Theokas, Lerner, Phelps, \& Lerner, 2006). How youth benefit from their OST activity participation is likely to depend on the combination of activities, structured and unstructured, in which they are involved (Zarret, et al., in press) and the contexts in which these activities happen. In other words, the effect of participation in a particular activity/program depends on other activities in which a youth is also involved, and the activities in which he or she fails to be involved. Adapting this broadened, systemic perspective is critical for youth development program designers and practitioners to fulfill their mission of being a key resource in promoting positive youth development (Theokas, et al., 2006), as this mission is unlikely to be fulfilled without the collaboration offered by parents and the community.

Finally, despite the realization that schools are a central context of child development, how school engagement impacts the psychological and behavioral well-being of youth remains in need of greater elucidation. Instead, the effects of school engagement have perhaps unduly focused on academic outcomes. This study assessed whether there was empirical support for the premise that student engagement in school is not only essential to positive academic outcomes, but also is beneficial to healthy emotional and behavioral functioning among youth. This idea was corroborated by the results showing that school engagement was positively associated with academic achievement and negatively associated with depression and risk behavior. In light of these results, it is legitimate to argue that youth experiences in school can potentially promote developmental competencies that pertain to academic, emotional, and behavioral functioning.

It is important to bear in mind that a particular level of school engagement, behavioral or emotional, results from the interactions of the individual and the context, not from youth themselves. Out-of-school time activities, such as civic activities and family activities may afford opportunities for youth to practice positive interaction with parents, other adult role models, and peers. The present findings highlight the notion that collaboration between in-school educators and out-of-school time educators is needed to promote positive healthy youth development.

The present results must be tempered in light of several limitations of the present study. First, the analyses are cross-sectional, so we cannot determine the direction of effects between activity participation, school engagement, and indicators of youth development. It is likely that youth who are behaviorally and emotionally engaged in school have the self-regulatory capacities to organize their daily life, which give them more time to be involved in constructive out-of-school activities. Longitudinal analyses are needed to understand the causal ordering among activity participation, school engagement, and youth development (Zarrett, et al., in press). Second, our list of activities was not exhaustive, due to constraints on the length of the survey we administered. Moreover, in the present report, activities such as sports, after school programs, and religious activities were not included in the analysis. Third, the present analyses focused only on the frequency of involvement, and not on the quality of activity participation. Nothing was assessed about what was going on within activity contexts, which limits our ability 
to target the components within activities that are responsible for promoting positive youth development.

Despite the above limitations, the present findings do have implications for applications in designing and implementing structured out-of-school program and in guiding youth in spending their time. This study adds to the extant literature by indicating that the extent to which a youth is engaged in in-school activities and out-of-school time activities has significant impacts on academic, emotional, and behavioral development. Activities that require little adult supervision for large amounts of time, such as hanging out with friends and media use, may impact negatively engagement in school and constructive out-of-school time activities.

\section{References}

Bachman, J.G., Johnston, L.D., \& O'Malley, P.M. (2000). Monitoring the future: A continuing study of American youth. Ann Arbor, MI: University of Michigan, Survey Research Center.

Compañ, E., Moreno, J., Ruiz, M.T., \& Pascual E. (2002). Doing things together: adolescent health and family rituals. Journal of Epidemiology and Community Health, 56, 89-94.

Dotterer, A.M., McHale, S.M., \& Crouter, A.C. (2007). Implications of out-of-school activities for school engagement in African American adolescents. Journal of Youth and Adolescence, 36, 4, 391-401.

Eccles, J. (2005). The present and future of research on activity settings as developmental contexts (pp. 353-371). In J.L. Mahoney, R.W. Larson, \& J.S. Eccles (Eds.), Organized activities as contexts of development. Majwah. NJ: Lawrence Erlbaum Associates.

Eccles, J.S., \& Barber, B.L. (1999). Student council, volunteering, basketball or marching band: What kind of extracurricular involvement matters? Journal of Adolescent Research, 14 (1), 1043.

Eisenberg, M.A., Olson, R.E., Neumark-Sztainer, D., Story, M., \& Bearinger, L.H. (2004). Correlations between family meals and psychosocial well-being among adolescents. Archives of Pediatrics and Adolescent Medicine, 158, 8, 792-796.

Finn, B. (1991). Young people's participation in post-compulsory education and training: Report of the Australian Education Council Review Committee. Retrieved June, 23, 2008 from http://www.voced.edu.au/docs/dest/TD LMR 85 641.pdf

Finn, J.D., \& Rock, D.A. (1997). Academic success among students at risk for school failure. Journal of Applied Psychology, 82(2), 221-234.

Flanagan, C., \& Faison, N. (2001). Youth civic development: Implications for research for social policy and programs. Social Policy Report, XV (1). Ann Arbor, MI: Society for Research on Child Development.

Fredricks, J.A., Blumenfeld, P.C., \& Paris, A.H. (2004). School engagement: Potential of the concept, state of the evidence. Review of Educational Research, 74, 1, 59-109. 
Jelicic, H., Bobek, D., Phelps, E., D., Lerner, J.V., Lerner, R.M. (2007). Using positive youth development to predict contribution and risk behaviors in early adolescence: Findings from the first two waves of the 4-H Study of Positive Youth Development. International Journal of Behavioral Development, 31(3), 263-273.

Jordan, W., \& Nettles, S.M. (2000). How students invest their time outside of school: Effects on school-related outcomes. Social Psychology of Education, 3, 217-243.

Larson, R.W., Branscomb, A.R., \& Wiley, K.R. (2006). Forms and functions of family mealtimes: Multidisciplinary perspectives. New Directions for Child and Adolescent Development,111, 1-15.

Larson, R.W., Hansen, D., \& Moneta, G. (2006). Differing profiles of developmental experiences across types of organized youth activities. Developmental Psychology, 42(5), 849-863.

Leffert, N., Benson, P.L., Scales, P.C., Sharma, A.R., Drake, D.R., \& Blyth, D.A. (1998). Developmental assets: Measurement and prediction of risk behaviors among adolescents. Applied Developmental Science, 2(4), 209-230.

Lerner, R.M. (2007). The Good Teen: Rescuing Adolescents from the Myths of the Storm and Stress Years. New York, NY: The Crown Publishing Group.

Lerner R.M. (2004). Liberty: Thriving and civic engagement among American youth. Thousand Oaks, CA: Sage.

Lerner, R.M., Lerner, J.V., Almerigi, J., Theokas, C., Phelps, E., Gestsdottir, S., \& et al. (2005). Positive youth development, participation in community youth development programs, and community contributions of fifth grade adolescents: Findings from the first wave of the 4-H Study of Positive Youth Development. Journal of Early Adolescence, 25, 17-71.

Mahoney, J.L., Parente, M.E., \& Zigler, E.F. (in press). After-school program participation and children's development. Invited chapter to appear in J. Meece \& J. S. Eccles (Eds.), Handbook of research on schools, schooling, and human development.

Mahoney, J.L., Harris, A.L., \& Eccles, J.S. (2006). Organized activity participation, positive youth development, and the over-scheduling hypothesis. Social Policy Report, 20(4), 1-31.

Radloff, L.S. (1977). The CES-D scale: A self-report depression scale for research in the general population. Applied Psychological Measurement, 1, 385-401.

Roth, J.L., \& Brooks-Gunn, J. (2003). What exactly is a youth development program? Answers from research and practice. Applied Developmental Science, 7, 92-109.

Sherrod, L.R. (2007). Civic engagement as an expression of positive youth development. In R.K. Silbereisen \& R.M. Lerner (Eds.). Approaches to positive youth development. London: Sage Publications. 
Theokas, C., \& Lerner, R.M. (2006). Observed ecological assets in families, schools, and neighborhoods: Conceptualization, measurement and relations with positive and negative developmental outcomes. Applied Developmental Science, 10(2), 61-74.

Verba, S., Schlozman, K.L., \& Brady, H.E. (1995). Voice and equality: Civic voluntarism in American politics. Cambridge: Harvard University Press.

Wong, C.A., \& Rowley, S.J. (2001). The schooling of ethnic minority children: Commentary. Educational Psychologist, $\underline{36}(\underline{1}), 57-66$.

Zarrett, N., Fay, K., Li, Y., Carrano, J., Phelps, E., \& Lerner, R. (in press). More than Child's Play: Variable- and Pattern-Centered Approaches for Examining the Effects of Sports Participation on Youth Development. Developmental Psychology.

Zarrett, N., \& Eccles, J. (2006). The passage to adulthood: Challenges of late adolescence. New directions for youth development, 111, 13-28.

(C) Copyright of Journal of Youth Development Bridging Research and Practice. Content may not be copied or emailed to multiple sites or posted to a listserv without copyright holder's express written permission. Contact Editor at: patricia.dawson@oregonstate.edu for details. However, users may print, download or email articles for individual use.

ISSN 2325-4009 (Print); ISSN 2325-4017 (Online) 